\title{
Virgínia Leone Bicudo: Pioneira da Psicologia e da Psicanálise no Brasil
}

\author{
Jorge Luís Ferreira Abrão * \\ Universidade Estadual Paulista, Assis, Brasil
}

\begin{abstract}
RESUMO
Este artigo tem por objetivo compor um esboço biográfico que trace a trajetória profissional de Virgínia Bicudo, destacando suas contribuições como pioneira da psicologia e da psicanálise no país. Assim, realizou-se um estudo qualitativo de natureza histórica, que empregou fontes orais e fontes documentais. Os resultados apontam que a atuação de Virgínia Bicudo tem duas fases distintas. A primeira, desenvolvida nas décadas de 1940 e 1950, voltada à aproximação entre a psicanálise e a saúde mental, por intermédio de ações preventivas junto a crianças com problemas escolares ou por intermédio da divulgação de informações relativas à educação infantil nos meios de comunicação. A segunda, que percorre as décadas de 1960 a 1980, caracteriza-se pela difusão do movimento psicanalítico no país.
\end{abstract}

Palavras-chave: Psicanálise; Brasil; História.

\begin{abstract}
Virgínia Leone Bicudo: pioneer of psychology and psychoanalysis in Brazil

This article aims to compose a biographical sketch that delineates Virginia Bicudo's career, highlighting her contributions as a psychology and psychoanalysis' pioneer in the country. That way, it was performed a qualitative study of historical nature which employed oral sources and documentary sources, The results show that the performance of Virginia Bicudo has two distinct phases. The first, was developed in the 1940s and 1950s, is focused on the approach of psychoanalysis and mental health, through preventive actions with children who had problems in school or through the dissemination of information related to early childhood education in the media. The second, which covers 1960 to 1980 decades, is characterized by the diffusion of the psychoanalytic movement in the country.
\end{abstract}

Keywords: Psychoanalysis; Brazil; History.

Virgínia Leone Bicudo é amplamente reconhecida no meio psicanalítico como personagem de grande expressão, responsável por iniciativas pioneiras voltadas à estruturação e difusão da psicologia e da psicanálise no país. Tal afirmativa pode ser corroborada mediante a análise de diversas pesquisas historiográficas, entre as quais destacamos: (Campos, 2001), (Mokrejes, 1993), (Abrão, 2001, 2004), (Perestrello, 1992), (Sagawa, 1994) e (Oliveira, 2006). Embora nenhuma das pesquisas mencionadas tenha por objetivo descrever a trajetória profissional de Virgínia Bicudo é possível identificar várias indicações históricas que reconhecem esta psicanalista como personagem de expressão não só para a história da psicanálise, mas também para memória histórica da cultura brasileira. Vejamos os fatos que sustentam esta afirmação: Virgínia Bicudo foi a primeira mulher na América Latina a deitar-se em um divã analítico ao iniciar, em 1937, análise didática com Adelheid Koch; foi fundadora, em 1944, do Grupo Psicanalítico de São Paulo, precursor da Sociedade Brasileira de Psicanálise de São Paulo (Sagawa, 1994) e figura como fundadora da Sociedade de Psicanálise de Brasília na década de 1970.

\footnotetext{
* Endereço para correspondência: Jorge Luís Ferreira Abrão - jlfabrao@gmail.com
} 
Assim, a presente pesquisa ${ }^{1}$ tem por objetivo compor um esboço biográfico de Virgínia Leone Bicudo que será narrado em um duplo movimento, conjugando dois fatores centrais que se sobrepõem: a mulher, enquanto representante das características socioculturais de sua época, particularmente a emancipação feminina ocorrida ao longo do século XX, e a psicanalista, na condição de pioneira do movimento que ajudou a difundir no país.

A consecução deste objetivo pressupõe a necessidade da identificação de meios adequados para o levantamento das informações necessárias, de forma a encontrar um conjunto de fatos e acontecimentos que sejam simultaneamente, relevantes e fidedignos,

Feita esta consideração, delimitamos como fontes históricas para esta pesquisa os depoimentos orais e a análise de documentos disponíveis em arquivos, que conjuntamente garantem o levantamento de um número expressivo de informações sobre Virgínia Bicudo e os contextos familiar, profissional e social em que viveu.

A partir das últimas décadas do século XX a história oral passou a ocupar um lugar de maior destaque na historiografia. Dentre os principais fatores responsáveis por esta mudança cabe destacar: o advento, a partir das primeiras décadas do século $\mathrm{XX}$, de uma nova concepção de história originado na França que ficou conhecido como "História Nova" (Le Goff \& Nora, 1974/1988a, 1974/1988b, 1974/1988c), que deslocou o interesse dos grandes eventos políticos para os fatos cotidianos; e a incorporação dos acontecimentos contemporâneos como objeto de estudo da história, fazendo com que o testemunho vivo de personagens que protagonizaram partes de uma história ainda não tão distante no tempo, fosse incorporado como objeto de estudo.

Neste sentido, empregamos a história oral por considerá-la um meio eficaz para obter informações sobre a vida pessoal e profissional de Virgínia Bicudo, uma vez que foi possível identificar um expressivo número de pessoas que conviveram com esta psicanalista. Assim, foram entrevistados os seguintes psicanalistas: Antônio Luiz Serpa Pessanha, Myrna Pia Favilli, Sonia Maria Sawaya Botelho Bracher, Maria Helena Teperman, Izelinda Garcia de Barros, Roberto Kehdy, Paulo Cesar Sandler e Laertes Moura Ferrão. Além destes profissionais foram ouvidos: Adele Pagni Lacotis, secretária da Sociedade Brasileira de Psicanálise de São Paulo e Rosa Lúcia Zingg, sobrinha de Virgínia Bicudo e curadora de seu espolio.

Com relação à pesquisa das fontes documentais em arquivos, identificamos dois grandes acervos. O primeiro relativo às obras publicadas por Virgínia Bicudo que, em sua grande maioria encontram-se disponíveis na biblioteca da Sociedade Brasileira de Psicanálise de São Paulo, exceção aos primeiros trabalhos publicados na década de 1940, como sua dissertação de mestrado e alguns artigos publicados em periódicos, disponível na biblioteca da Fundação Escola de Sociologia e Política de São Paulo.

Uma vez realizado este levantamento podemos destacar três grandes períodos que caracterizaram a sobreposição entre a vida profissional de Virgínia Bicudo e acontecimentos pioneiros da psicologia e da psicanálise no Brasil. 1. O período de formação, que vai desde o seu nascimento até os anos de formação acadêmica; 2. A dimensão social da psicanálise, que se caracteriza pela aplicação da psicanálise em diferentes frentes de atuações com abrangência social; e 3. Difusão e institucionalização da psicanálise no Brasil, período em que Virgínia Bicudo assumiu posição de destaque na Sociedade Brasileira de Psicanálise de São Paulo.

\section{OS ANOS DE FORMAÇÃO}

Virgínia Leone Bicudo nasceu em 21 de novembro de 1910, na cidade de São Paulo. Os anos que se seguiram ao seu nascimento consagraram-se como um período marcado por inúmeras transformações na vida econômica, cultural e social da cidade, oscilando entre um modelo provinciano de relações e a urbanização acelerada, que se tornaria a marca distintiva da futura metrópole.

Esquadrinhando a trajetória pessoal de Virgínia Bicudo, a partir de sua origem familiar até sua forte ascendência profissional junto ao universo psicanalítico brasileiro, é possível reconhecer a existência de muitos elementos representativos da estrutura sociocultural brasileira que se consolidou ao longo do século XX. Sua origem familiar humilde e o seu posterior reconhecimento profissional, concretizado através do pioneirismo e da posição de liderança que assumiu no 
universo psicanalítico do país, faz ressoar a imagem do mito convertido em realidade. Percorrendo alguns fragmentos de sua história pessoal é possível compreender como estes elementos coadunam-se de forma a forjar a representação ora referida.

De um lado, Joana Leone Bicudo, mãe de Virgínia Bicudo, é natural da Catânia, cidade italiana localizada na Sicília onde nasceu em 2 de dezembro de 1887. Imigrou para o Brasil quando contava dez anos de idade, juntamente com uma leva de imigrantes evacuados da Itália que chegavam ao país no final do século XIX com a missão de substituir a mão de obra escrava. Desta forma, Pietro Paolo Leone e Agripina Palermo, avós maternos de Virgínia Bicudo, juntamente com os quatro filhos, instalaram-se na Fazenda Matto Dentro localizada no município de Campinas no Estado de São Paulo.

As aspirações da família Leone quanto às possibilidades de prosperar economicamente em solo brasileiro ilustram antes uma imagem que fora difundida na Europa no final do século XIX. "Este mundo imaginário de um Brasil afável e gentil onde tudo se multiplicava à larga, permeou parte do campo europeu do século XIX” (Alvim, 1998, p. 219).

Por outro lado, seu pai, Theofilo Julio Bicudo nasceu em 9 de janeiro de 1887, na Fazenda Matto Dentro, onde viveu até os anos de juventude. De acordo com as informações que chegaram a Rosa Lúcia Zingg, por intermédio de sua mãe Maria de Lourdes Bicudo Zingg, é possível supor que seu avô era filho do Coronel Bento Bicudo com uma escrava de sua fazenda, cujo nome é desconhecido na atualidade. Em 1905 mudou-se para São Paulo com o intuito de dar continuidade aos seus estudos, tornou-se funcionário público lotado nas Agências Brasileiras de Correios e Telégrafos, tendo na juventude acalentado o sonho de cursar medicina. Paralelamente ao seu ofício nos Correios, dedicou-se a dar aulas particulares que eram realizadas em sua casa, destinadas a preparação de candidatos para o vestibular de medicina.

Os dados destacados acima, nos remetem a duas conclusões sobre Virgínia Bicudo. A primeira diz respeito à origem étnica da família Bicudo: a condição de seu pai como descendente de escravos, em uma sociedade que começava muito lentamente a se refazer do trauma da escravidão, e a condição de sua mãe como imigrante italiana, em um momento em que os imigrantes eram reconhecidos pelas elites brasileiras como um "mal necessário", provavelmente fez com que a família Bicudo enfrentasse diversas manifestações de preconceito. A segunda conclusão indica que a família Bicudo era proveniente de uma origem social humilde e, em contrapartida a esta realidade, buscava guindar-se a um posição social que conferisse maior status e conforto, esta foi a intenção dos pais de Joana Leone ao saírem da Itália em direção a terra prometida e de Theofilo Julio Bicudo ao deixar o interior buscando melhores oportunidades de estudo na capital, embalado por seu pendor para a atividade intelectual que ao longo de toda sua vida foi uma importante referência identitária.

Assim constatamos que Virgínia Bicudo foi fortemente investida por uma representação mítica em seu universo familiar, que identificavam nela grande potencial para ascensão social por intermédio de sua capacidade intelectual.

Complementarmente encontramos no imaginário popular reinante entre os habitantes de São Paulo da década de 1920 uma visão mítica fundada na crença em uma identidade coletiva que conferia aos paulistanos singularidade, distinguível por meio de algumas características que lhe eram peculiares, como a constituição étnica, formada a partir da miscigenação de indivíduos de várias origens raciais vivendo de forma harmoniosa e construtiva, e a emergência de um centro urbano marcado pela tolerância e igualdade de oportunidades a todos os povos, o que garantiria oportunidade de sucesso e êxito para todos aqueles que tivessem iniciativa e espírito de conquista. Evidentemente tal conquista era uma condição distante da realidade da grande maioria da população que enfrentava condições de vida bastante precárias e poucas oportunidades de desenvolvimento pessoal e profissional em uma sociedade fortemente marcada pelo preconceito. Fato este designada por Nicolau Sevcenko no livro "Orfeu Extático na metrópole: São Paulo, sociedade e cultura nos frementes anos 20" como o mito de Babel.

O mundo novo representado por São Paulo, onde primeiro o branco se fundiu com o índio, depois os descendentes destes se cruzaram com os negros, e agora as novas gerações se consorciam com os fugitivos da Europa convulsionada, é a nova terra da promissão, onde se vão erguer as torres sólidas das "novas arquiteturas da sociedade futura", a Babel 
invertida, a Babel que une e, portanto, leva ao clímax, à consumação da função mística que sua antecessora frustrara [...]. Mais do que o mito de Babel, nesta ordem de metáforas, São Paulo para estes grupos evocaria o Cativeiro da Babilônia. (Sevcenko, 1992, p. 38-39)

Da conjugação destes fatores encontraremos em Virgínia Bicudo uma forte propensão e aptidão para a atividade intelectual associada a uma aguçada percepção das experiências de preconceito sofridas ao longo da vida. Dando vazão as aspirações intelectuais da família, Virgínia Bicudo ingressou na Escola Normal Caetano de Campos onde concluiu o Curso Normal em 1930. Esta Escola, fundada em 1846, representou um marco para a educação paulistana ao se destacar como uma instituição modelo que incorporou propostas pedagógicas de vanguarda. Foi nesta instituição que Virgínia Bicudo entrou em contato direto com o preconceito e a discriminação racial, experiência que a impulsionou a procurar o Curso de Ciências Sociais concluído em 1938 pela Escola Livre de Sociologia e Política de São Paulo e posteriormente a enveredar pela psicanálise. Este fato foi narrado pela própria Virgínia Bicudo em 1994 em entrevista concedida ao jornal Folha de São Paulo.

O que me levou para a psicanálise foi o sofrimento. Eu queria me aliviar de sofrer. Imaginava que a causa do meu sofrimento fossem problemas sociais, culturais. Então me matriculei na Escola de Sociologia e Política. Isso foi em 1935. Eu tinha conflitos muito grandes comigo mesma, mas achava que a causa era social. Desde criança eu sentia preconceito de cor. (Bicudo, 1994, p. 6)

O tema do preconceito racial e as tentativas de elaborá-lo foram fatos recorrentes na vida de Virgínia Bicudo. Uma das alternativas encontradas por esta psicanalista para arrefecer as angústias mobilizadas pelo preconceito foi a tentativa de compreendê-lo no platô intelectual. Neste sentido, em 1945, já como professora da Escola Livre de Sociologia e Política de São Paulo, Virgínia Bicudo defendeu sua dissertação de mestrado intitulada "Estudo de Atitudes Raciais de Pretos e Mulatos em São Paulo", cujo objetivo foi investigar as atitudes raciais de pretos e mulatos, uma vez que as atitudes expressam a natureza própria do indivíduo em interação com as condições sociais vivi- das, de tal modo que as atitudes "[...] representam os aspectos estáveis e organizados da personalidade que tendem a persistir enquanto funcionar bem e permitir a conduta para proceder de um modo satisfatório" (Bicudo, 1945, p. 1-2). Além da evidente conotação pessoal que envolvia o tema deste trabalho, o pioneirismo com que aborda o tema, deslocando os estudos raciais das discussões biológicas em favor de uma visão que levava em consideração as condições sociais e culturais, constitui-se em um marco histórico ${ }^{2}$.

Foi durante o Curso de Ciências Sociais que Virgínia Bicudo entrou em contato pela primeira vez com a psicanálise, por intermédio de Noemy Silveira Rudolfer $^{3}$ que ministrava a disciplina de Psicologia Social, concitando esta jovem mulher a buscar formação psicanalítica, em uma época em que o tema era bastante escasso no Brasil.

Em 1936, Virgínia Bicudo foi orientada a procurar Durval Marcondes ${ }^{4}$ para que pudesse dar vazão ao seu anseio de estudar psicanálise. Rememorando seus primeiros movimentos de aproximação com a psicanálise, comentou Virgínia Bicudo em 1977.

Então, eu saí por São Paulo procurando onde se estudava psicanálise. E foi assim que comecei. Disseram-me que havia uma pessoa que estudava psicanálise, que era o Durval Marcondes. Procurei conversar com ele. Tudo bem... "Eu sou estudante e estou interessada em fazer cursos, estudos sobre a psicanálise. Disseram-me que o senhor é quem podia me orientar e então eu queria saber quando poderia começar". Ele disse-me: "você estudar psicanálise? Formação em psicanálise"? Eu disse. "Quero". "A senhora sabe o que é isso?". "Bem, eu li alguma coisa sobre inconsciente, sobre sublimação...". "A senhora não sabe onde vai entrar! Sabe que vai ter toda a sociedade contra a senhora? Sabe que há um preconceito contra a sexualidade e a senhora vai estudar isso?". Bem, eu não tinha noção sobre o que ele estava alertando, que era perigoso, que precisava pensar muito. "Se a senhora está resolvida, vá para casa, peça permissão a seu pai, e volte aqui. Se ele permitir então eu posso indicar como fazer." Assim eu fui para casa obter a permissão de meu pai, mas eu não tinha mais pai, nesta época. No dia seguinte eu o procurei e disse: "Olha, eu estou de volta e decidida. Meu pai disse que sim, que eu posso". "Então se é assim, eu vou apresentá-la a uma senhora, Dra. Koch, que veio da Alemanha e que vai iniciar aqui formação de analistas.” (Bicudo, 1977, p. 8) 
Nesta ocasião, Durval Marcondes mantinha contato com Ernest Jones (1879-1958), então presidente da IPA (International Psychoanalytic Association), para que Adelheid Lucy $\mathrm{Koch}^{5}$ imigrasse para o Brasil, com a finalidade de conduzir a formação analítica de um grupo de profissionais interessados em psicanálise. Em 1937 Virgínia Bicudo deu início a sua análise didática com Adelheid Koch, uma das atividades requeridas para a formação analítica, e pouco depois iniciou a análise de seus primeiros pacientes.

O grupo formado no entorno de Adelheid Koch, integrado por Durval Marcondes, Darcy de Mendonça Uchoa $^{6}$, Flávio Dias ${ }^{7}$ e Virgínia Bicudo foi oficialmente reconhecido como Grupo de Psicanálise de São Paulo pela IPA em 1944, posteriormente este grupo já contando com outros integrantes foi elevado à categoria de Sociedade Brasileira de Psicanálise de São Paulo em 1951.

Ao analisarmos o entorno que sustenta a formação deste primeiro grupo de psicanálise, a presença de Virgínia Bicudo como a única mulher a se analisar com Adelheid Koch, neste momento ${ }^{8}$, ganha destaque, na medida em que coloca em debate o papel da mulher na sociedade paulistana nas primeiras décadas do século XX e sua relação com a psicanálise.

A partir do final da década de 1930 e particularmente durante a década de 1940, o papel da mulher na sociedade urbana, entendido a princípio como uma extensão da figura masculina, primeiro do pai e depois do marido, começou a ser questionado, de forma que a mulher passa a reivindicar uma identidade social que passa, obrigatoriamente, pelo reconhecimento profissional. A inserção da psicanálise no Brasil, neste período, contribuiu não só para que muitas mulheres encontrassem uma identidade profissional como psicanalistas, mas também, de forma bem mais abrangente, trouxe a tona o debate relativo à sexualidade e as relações de gênero. Gilberto Rocha (1989) ao relatar o contexto social que marca a introdução da psicanálise no Brasil comenta que a psicanálise foi introduzida no país no mesmo período em que as mulheres buscavam uma redefinição de seu papel social. Neste contexto, Virgínia Bicudo soube aproveitar o momento histórico em que estava inserida, e adotar uma postura de vanguarda em relação a seus contemporâneos.

\section{A DIMENSÃO SOCIAL DA PSICANÁLISE}

Em 1938, na condição de educadora sanitária, título obtido em 1932 pelo Instituto de Higiene de São Paulo, Virgínia Bicudo passa a atuar como visitadora psiquiátrica da Clínica de Orientação Infantil da Seção de Higiene Mental Escolar, coordenada na ocasião por Durval Marcondes 9 . Esta instituição tinha por finalidade oferecer atendimento a crianças com problemas de aprendizagem matriculadas nas escolas da capital, sendo sua atuação centrada no diagnóstico e na orientação de país e professores. A filosofia que sustentava a ação da Clínica de Orientação Infantil estava alicerçada em três pilares fundamentais: a higiene mental, a "Escola Nova" e a psicanálise, sendo que todas estas influências estavam presentes no percurso profissional de Virgínia Bicudo.

Ao longo de aproximadamente uma década, Virgínia Bicudo ganhou particular projeção entre os profissionais que atuavam na Clínica de Orientação Infantil. Segundo Botelho (1989) o prestígio e a influência conquistados por Virgínia Bicudo levaram-na a ocupar a posição de orientadora ou conselheira das jovens que, egressas do Curso de Educadora Sanitária ou da Escola Normal, iniciavam sua vida profissional nesta instituição, conduzindo-as a formação universitária, que nesta ocasião, tendo em vista a inexistência de cursos de psicologia, eram orientadas a procurar o curso de pedagogia ou de filosofia.

Uma das áreas em que a prática profissional de Virgínia Bicudo ganhou particular destaque foi a atuação no campo da prevenção em saúde mental, mediante a divulgação de princípios relativos à educação infantil formulados na teoria psicanalítica. Dentre as várias iniciativas que ganharam ampla repercussão na década de 1950 cabe destacar três: o programa veiculado na Rádio Excelsior em 1950, a série de artigos publicados no jornal Folha da Manhã em 1954 e o livro Nosso Mundo Mental editado em $1956^{10}$. Estes trabalhos tinham por finalidade apresentar temas cotidianos relativos à educação infantil e demonstrar a forma mais adequada de abordá-los, tomando como referência os princípios da teoria psicanalítica.

Tendo em vista a inovação e o pioneirismo que este trabalho representou nas décadas de 1940 e 1950 , suas repercussões reverberaram em diferentes direções: inseriu a psicanálise no campo da prevenção em 
saúde mental e fomentou o debate sobre a criação da profissão de psicólogo.

No tocante ao primeiro aspecto, evidenciamos que a psicanálise foi inserida campo da saúde mental por intermédio do desenvolvimento de uma prática preventiva, através da qual a atenção às manifestações sintomáticas da criança em idade escolar era entendida como um caminho para evitar a ocorrência de transtornos mentais na vida adulta.

$\mathrm{Na}$ tentativa de compreender as práticas preventivas inspiradas na psicanálise que sustentaram o trabalho desta autora nas décadas de 1940 e 1950, devemos, a título de esclarecimento, contextualiza-la no movimento higienista surgido no Brasil nas primeiras décadas do século XX. Cabe considerar que o trabalho de Virgínia Bicudo no campo da prevenção guarda relações com o movimento higienista, porém, inova em relação a ele. A filosofia higienista exerceu grande influência nas políticas de saúde pública nas primeiras décadas do século XX, cujo reflexo foi sentido no campo da saúde mental com a adoção de várias práticas de caráter profilático. Segundo Jurandir Freire Costa,

Sobretudo a partir de 1926, os psiquiatras começaram a enunciar suas novas concepções de prevenção. Eles pretendiam tornar a prevenção psiquiátrica similar a prevenção em medicina orgânica. A ação terapêutica deveria exercer-se no período prépatogênico, antes do aparecimento dos sinais clínicos. Esta concepção leva-os a dedicar um maior interesse a prevenção da saúde mental. Daquele momento em diante, o alvo de cuidado dos psiquiatras passou a ser o indivíduo normal e não o doente. $\mathrm{O}$ que interessava era a prevenção e não a cura. (Freire Costa, 1976, p. 33)

Assim, as primeiras aproximações com a psicanálise sustentavam-se em propostas de caráter profilático que tinha como finalidade intervir antes do aparecimento de um estado patogénico, de forma a favorecer o desenvolvimento de indivíduos saudáveis, por intermédios de práticas que muito se aproximavam da eugenia. A inovação contida no trabalho preventivo desenvolvido por Virgínia Bicudo ganha destaque por distanciar-se da conotação eugênica, na medida em que considerava as manifestações sintomáticas da criança para, na sequencia, propor as orientações necessárias a pais e educadores.
Com relação ao segundo aspecto, a prática profissional das visitadoras psiquiátricas, que estavam incumbidas de realizar entrevistas e orientações com pais e professores e fazer psicoterapia com a criança, e das psicologistas, a quem cabia realizar a aplicação dos testes psicológicos, introduziu oficialmente a função de psicólogo no serviço público paulista desde o final da década de 1930, fomentando o debate relativo à criação dos cursos de psicologia e à regulamentação da profissão de psicólogo ${ }^{11}$.

Da conjugação entre as características do movimento psicanalítico em São Paulo, que possibilitaram o surgimento de analistas não médicos, com uma personalidade resoluta que soube perscrutar oportunidades e utilizá-las com consistência em sua vida pessoal e profissional, emerge a figura de Virgínia Bicudo que, em um intervalo de aproximadamente vinte anos, projetou-se como uma psicanalista bem-sucedida que trazia como diferencial o fato de ter obtido, sobretudo no início da década de 1950, grande exposição na mídia, o que fazia dela uma profissional reconhecida publicamente.

Este reconhecimento público aliado aos embates travados entre a psicanálise e a psiquiatria acadêmica em São Paulo, resultou em severas críticas a prática clínica de Virgínia Bicudo, uma vez que esta profissional exercia a psicanálise sem possuir formação médica. Os reflexos deste embate reverberarão de forma mais contundente em 1954 durante o I Congresso Latino Americano de Saúde Mental, ocasião em que, ao apresentar uma comunicação relativa ao trabalho realizado na Clínica de Orientação Infantil, Virgínia Bicudo foi publicamente acusada de charlatanismo. Entre seus críticos figuravam nomes de destaque da psiquiatria paulista como Antônio Carlos Pacheco e Silva (1898-1988), que defendiam a restrição do exercício da psicanálise apenas a profissionais com formação médica.

Embora as críticas fossem encaminhadas diretamente a Virgínia Bicudo, a intenção de seus detratores era a de atacar a psicanálise, que começava ganhar projeção em São Paulo. Segundo Plínio Montagna, a psiquiatria paulistana "ao se mostrar ao continente, não podia prescindir da psicanálise e da experiência de seus praticantes, em São Paulo. Mas notamos, também, uma psiquiatria "ciumenta" dos voos próprios do movimento psicanalítico" (Montagna, 1994, p. 36). 
Na medida em que as críticas e acusações de charlatanismo avolumavam-se, provocando em Virgínia Bicudo o recrudescimento de sentimentos de exclusão, esta psicanalista lançou-se em uma nova iniciativa intelectual, buscando aperfeiçoamento profissional na Inglaterra, que na ocasião era a principal referência da psicanálise mundial. Residiu em Londres no período de 1955 e 1959, frequentou o Instituto de Psicanálise de Londres e a Clínica Tavistock, nestas instituições teve contato direto com vários expoentes do grupo kleiniano, como Hebert Rosenfeld, Hanna Segal, Wilfred Bion e, particularmente, Melanie Klein.

\section{DIFUSÃO E INSTITUCIONALIZAÇÃO DA PSICANÁLISE NO BRASIL}

$O$ regresso ao Brasil marca o final de um ciclo na vida de Virgínia Bicudo, e a partir desse momento engaja-se em grandes projetos que ganharão repercussão no cenário psicanalítico nacional, assumindo uma posição de liderança na Sociedade Brasileira de Psicanálise de São Paulo e passando a desfrutar de grande reconhecimento público. Em contrapartida, as iniciativas de abrangência social que desenvolveu anos antes, foram gradualmente perdendo espaço em sua atuação profissional. Ao menos dois fatores concorreram para este redirecionamento: o golpe militar de 1964 que desarticulou iniciativas de abrangência social e o deslocamento dos seus interesses para uma atuação clínica e didática dentro da Sociedade Brasileira de Psicanálise de São Paulo.

Desde seu regresso ao Brasil, Virgínia Bicudo passou a ser muito requisitadas por diversos psicanalistas e candidatos em formação analítica, que desejavam aprimorar seu conhecimento teórico e técnico sobre a teoria kleiniana, tema no qual Virgínia Bicudo havia adquirido amplo conhecimento mediante um profícuo contato com Melanie Klein.

$\mathrm{O}$ reconhecimento e a credibilidade conferidos a Virgínia Bicudo, aliados a uma personalidade afeita à liderança, fizeram com que essa psicanalista assumisse posição de destaque junto à Sociedade Brasileira de Psicanálise de São Paulo, sendo eleita secretária da Sociedade para o biênio 1961 a 1963 e, a partir de março de 1961, integrou, juntamente com Adelheid Koch, Darcy Uchoa, Lygia Amaral, Isaias Melsohn e Henrique Schlomann, a Comissão de Ensino, órgão encarregado de gerir a formação de novos psicanalistas, que deu origem ao Instituto de Psicanálise (Barcellos, 1976), cargo ocupado até 1973.

Outra frente de atuação que teve grande repercussão para a psicanálise brasileira foram as iniciativas editoriais que empreendeu na década de 1960 . O primeiro periódico a ser editado foi o Jornal de Psicanálise, idealizado por Virgínia Bicudo com a finalidade de divulgar os trabalhos produzidos pelos candidatos do Instituto de Psicanálise, sendo que seu primeiro número, publicado em 1966. Em 1967, uma iniciativa mais ousada começa a tomar forma com a publicação do primeiro número da Revista Brasileira de Psicanálise, destinada a tornar-se um veículo de comunicação oficial da Sociedade Brasileira de Psicanálise de São Paulo. Assim, um grupo de analistas constituído por Durval Marcondes, Virgínia Bicudo, Luiz Almeida Prado Galvão, Laertes Ferrão e Armando Ferrari, buscaram reunir as condições necessárias, tanto técnicas quanto financeiras, para editarem a Revista (Galvão, 1967). Para tal, contaram com o apoio do empresário José Nabantino Ramos, com larga experiência no ramo editorial. Superadas as dificuldades iniciais, a Revista foi lançada em 1967 por ocasião da realização da I Jornada Brasileira de Psicanálise.

Na década de 1970, Virgínia Bicudo lança-se em uma nova empreitada, dedicando-se à difusão da psicanálise no Brasil, fato que resultou na criação da Sociedade de Psicanálise de Brasília. Alguns fatores concorreram para que Virgínia Bicudo tomasse esta iniciativa, entre os quais destacamos: desde a década de 1950, quando soube da criação de Brasília, essa psicanalista viu-se atraída pela ideia de levar a psicanálise para a nova Capital do país; o arrefecimento, durante a década de 1970, da influência de Virgínia Bicudo sobre a Sociedade Brasileira de Psicanálise de São Paulo e, aliado a estes fatores, a crescente demanda da população brasileira por análise neste período (Figueira, 1991), fato que estimulou o interesse de diversos profissionais em fazer formação psicanalítica em diferentes regiões do país. No entendimento dessa psicanalista, ao invés de os profissionais interessados deslocarem-se para os poucos centros que possuíam formação psicanalítica no Brasil, nesta ocasião apenas São Paulo, Rio de Janeiro e Porto Alegre, seria mais adequado promover a migração de analistas habilita- 
dos e fomentar a criação de novos grupos de psicanálise no interior do país.

O processo de implantação da psicanálise em Brasília teve início em 1970, ocasião em que Virgínia Bicudo iniciou a análise de um grupo de psiquiatras que almejavam fazer a formação psicanalítica ${ }^{12}$. Somente em 1971, após serem superadas as primeiras resistências, as análises conduzidas por Virgínia Bicudo em Brasília foram oficialmente admitidas como análises didáticas e o Instituto de Psicanálise da Sociedade Brasileira de Psicanálise de São Paulo reconheceu o grupo de Brasília como uma sede avançada, que ficou conhecida como Sede Brasília da SBPSP.

Quando Virgínia Bicudo encerrou suas atividades em Brasília no início da década de 1990, A Sociedade Psicanalítica de Brasília já estava consolidada, uma vez que em 1994 o Grupo de Estudos de Psicanálise de Brasília foi oficialmente reconhecido pelo IPA, sendo integrado ao quadro de sociedades provisórias em 1999.

A partir da década de 1990, Virgínia Bicudo restringe suas atividades em São Paulo, dedicando-se exclusivamente a atendimentos clínicos e supervisões. Após ser submetida, em 1993, a uma cirurgia em decorrência de um aneurisma na aorta abdominal, Virgínia Bicudo foi gradualmente perdendo vitalidade até falecer em setembro de 2003.

Ao analisarmos o contexto histórico das décadas de 1960 e 1970 e 1980, período que circunscreve as iniciativas mais ousadas e originais de Virgínia Bicudo, percebemos coincidir com o período de maior expansão do movimento psicanalítico no país. Entre os fatores que impulsionaram o rápido crescimento da psicanálise a partir da década de 1970, com forte adesão de parcelas expressivas da população, em particular a classe média, destacamos: o processo de urbanização e modernização ocorrido no país e a desarticulação, a partir do golpe militar de 1964, de iniciativas de caráter social sustentadas na psicanálise, estimulando estratégias de natureza individual para a resolução dos conflitos, como a psicoterapia. Desta forma, "a "cultura psicanalítica brasileira" foi se organizando em torno do alto consumo de psicoterapia apoiada numa psicanálise difundida que opera de modo múltiplo, flexível e sutil como "mapa" para a orientação neste mar de incertezas" (Figueira, 1991, p. 225).
Neste sentido da conjugação entre a experiência adquirida na Inglaterra e a ascensão da cultura psicanalítica no país, encontramos as condições para que Virgínia Bicudo viesse a ocupar um lugar de liderança no senário psicanalítico nacional, exercendo influência na formação das futuras gerações de psicanalistas surgidas no Brasil.

Por outro lado, o declínio da influência de Virgínia Bicudo junto aos círculos psicanalíticos que ajudou a fundar, pode ser atribuído a dois fatores principais que ocorrem paralelamente a partir de meados da década de 1980: arrefecimento do interesse pela psicanálise no meio social, em decorrência do declínio de seu prestígio como principal recurso para a resolução de dificuldades emocionais, acompanhado do surgimento de outros modelos de psicoterapia, e expansão dos modelos teóricos adotados na psicanálise brasileira a partir da década de 1990, de forma tal que as influências freudianas e kleinianas, antes hegemônicas, foram sendo relativizadas com a introdução de outros autores, fato que conduziu a uma diminuição da influência e do prestígio de Virgínia Bicudo enquanto representante do pensamento kleiniano.

\section{CONSIDERAÇÕES FINAIS}

A relação entre a psicanálise e a vida de Virgínia Bicudo comporta diferentes dimensões, de tal forma que uma é constitutiva da outra enquanto representante da atmosfera de modernização da sociedade brasileira, que caracteriza as primeiras décadas do século $\mathrm{XX}$.

A forma como a psicanálise foi introduzida no Brasil no início do século XX, entendida como um sistema teórico capaz de subsidiar diferentes áreas do conhecimento, como a educação, o direito, a medicina a arte, entre outras, possibilitou diferentes leituras e interpretações da teoria psicanalítica. Se por um lado a psiquiatria da década de 1920 apropriou-se da psicanálise como um instrumental capaz de evitar o surgimento de transtornos mentais, subsidiando uma prática que muito se aproximava da eugenia (Costa, 1976); por outro lado, a aproximação entre a psicanálise e a arte, particularmente o movimento modernista, cujo ícone mais notório foi a Semana de Arte Moderna de 1922, criavam o substrato para expressões de vanguarda de uma sociedade em ebulição (Lobo, 1994). 
Particularmente em São Paulo, a chegada da psicanálise esteve envolta em uma aura de transformação e modernização social, esboçando uma forte relação com diferentes esferas da vida cultural da cidade, que começava a despontar rumo ao desenvolvimento.

Ao descobrir a psicanálise no final da década de 1930, por intermédio de Durval Marcondes e Adelheid Koch, Virgínia Bicudo encontrou não só respostas a uma série de inquietudes que a acompanhavam, dando um novo significado à sua vida pessoal, como também foi confrontada com uma nova dimensão em sua vida profissional, rica em possibilidades e alternativas. Neste sentido, a psicanálise foi o ponto de partida de diversas transformações ocorridas na vida de Virgínia Bicudo.

Dentre todas as atividades que exerceu e as responsabilidades que assumiu ao longo de aproximadamente cinquenta anos de exercício profissional enquanto psicanalista, um aspecto do trabalho de Virgínia Bicudo ganham particular destaque, sua constante preocupação em promover a expansão das fronteiras psicanalíticas. Suas ações neste sentido tomaram duas direções: inicialmente seu trabalho assumiu uma forte conotação social, procurando aproximar a psicanálise da educação de forma a beneficiar a educação infantil e compreender as dificuldades manifestadas pela criança; em um segundo momento as ações de Virgínia Bicudo foram direcionadas para a difusão das instituições psicanalíticas em diferentes regiões do país, contribuindo para a formação de um maior número de psicanalistas.

Tomemos em análise as iniciativas voltadas à aproximação entre psicanálise e educação, que Virgínia Bicudo protagonizou durante as décadas de 1940 e 1950, seja por sua prática como visitadora psiquiátrica da Clínica de Orientação Infantil da Seção de Higiene Mental Escolar ou por intermédio de ações voltadas a divulgação de informações relativas à educação infantil orientadas por princípios psicanalíticos em programas de rádios ou artigos jornalísticos.

Dois fatores contribuíram para o desenvolvimento de uma prática que colocou em relevo a dimensão social da psicanálise. Por um lado, a direção assumida pelo movimento psicanalítico em São Paulo que favoreceu a aproximação das idéias freudianas com a área das ciências humanas, fazendo com que práticas voltadas à aplicação da psicanálise em diferentes áreas do conhecimento fossem estimuladas, como, por exemplo, a educação. Por outro lado, o percurso acadêmico de Virgínia Bicudo até seu encontro com a psicanálise, iniciado na Escola Normal Caetano de Campos, passando pelo Curso de Educadora Sanitária no Instituto de Higiene de São Paulo e culminando com a formação em Ciências Sociais na Escola Livre de Sociologia e Política de São Paulo, fez com que esta psicanalista estivesse em constante sintonia com as demandas sociais de sua época, de tal modo que ao aproximar-se da psicanálise, soube apropriar-se deste referencial teórico para prover respostas e buscar soluções para os problemas e necessidades que identificava a partir de sua prática como educadora sanitária e visitadora psiquiátrica.

O grande destaque deste período recai sobre a série Nosso Mundo Mental, representada por programas radiofônicos apresentados na Rádio Excelsior e artigos jornalísticos publicados no jornal Folha da Manhã, ambas as iniciativas veiculadas na década de 1950. Nestes trabalhos, Virgínia Bicudo divulga orientações sustentadas em princípios psicanalíticos, destinadas a pais e educadores, procurando com isto fazer com que os benefícios da psicanálise estivessem acessíveis a um maior número de pessoas. Secundariamente, estas iniciativas, associadas a muitas outras surgidas no país, contribuíram para a popularização das ideias psicanalíticas entre a população brasileira, favorecendo o surgimento de um imaginário coletivo no qual a subjetividade passa a ser considerada como fator relevante no desenvolvimento da personalidade e na forma como são estabelecidas as relações sociais e afetivas.

Após regressar de Londres, Virgínia Bicudo afastou-se gradativamente das atividades em instituições públicas, deslocando o foco de sua atenção para o ensino da psicanálise dentro das Sociedades de Psicanálise. Entre os fatores que contribuíram para este redirecionamento estão as transformações políticas ocorridas no país a partir de meados da década de 1960 que desestimulou iniciativas sociais de grande repercussão e a crescente demanda da Sociedade Brasileira de Psicanálise de São Paulo que reivindicava a participação de Virgínia Bicudo na estruturação dos critérios para a formação de novos psicanalistas.

Assim, o interesse na difusão da psicanálise ganhou uma nova forma. Ao invés de dedicar-se à 
transmissão da psicanálise ao grande público, como fizera nas décadas de 1940 e 1950, Virgínia Bicudo passou, ao longo das décadas de 1960 a 1970, a interessar-se pela migração do movimento psicanalítico no país. Sua ação mais contundente neste sentido é representada pela idealização e pela fundação em 1970 de um núcleo voltado à formação de psicanalistas na Capital Federal sob o patrocínio da Sociedade Brasileira de Psicanálise de São Paulo, cujo êxito resultou, anos mais tarde, na criação da Sociedade de Psicanálise de Brasília enquanto instituição autônoma reconhecida pela IPA.

Ao tomar para si a responsabilidade de promover a difusão da psicanálise em diferentes regiões do território brasileiro, Virgínia Bicudo tornou-se pioneira, não só pela precedência de suas ações, como o fato de ter sido a primeira mulher analisada no Brasil, mas também pela força de suas iniciativas políticas e administrativas, que contribuíram para a expansão das fronteiras psicanalíticas.

\section{REFERÊNCIAS}

Abrão, J. L. F. (2004). A tradição kleiniana no Brasil: uma investigação histórica sobre a difusão do pensamento kleiniano. Tese de Doutorado, Instituto de Psicologia, Universidade de São Paulo, São Paulo.

Abrão, J. L. F. (2001). A história da psicanálise de crianças no Brasil. São Paulo: Escuta.

Alvim, Z. Imigrantes: a vida privada dos pobres do Brasil. In História da vida privada no Brasil (Vol. 3, pp. 215287). São Paulo: Companhia das Letras.

Bicudo, V. L. (1994, 5 de junho). "Já fui chamada de charlatã”. (Depoimento a Cláudio João Tognolli). Folha de S. Paulo, p. 6.

Bicudo, V. L. (1977). Entrevista: Adivinhe quem vem para jantar? uma conversa com a prof. Virgínia L. Bicudo. IDE, 3(4), 7-13.

Bicudo, V. L. (1956). Nosso mundo mental. São Paulo: Instituição Brasileiro de Difusão Cultural.

Bicudo, V. L. (1946). Funções da visitadora psiquiátrica na clínica de orientação infantil e noções de higiene mental da criança. In D. M. Marcondes (Org.). Noções gerais de higiene mental da criança (p. 79-89). São Paulo: Livraria Martins Editora.

Bicudo, V. L. (1945). Estudo de atitudes raciais de pretos e mulatos em São Paulo. São Paulo, 1945, 68 p. Dissertação (Mestrado). Escola Livre de Sociologia e Política de São Paulo.
Barcellos, R. (1976). Algumas anotações biográficas da Sociedade brasileira de psicanálise de São Paulo. São Paulo: SBPSP. (mimeo).

Campos, R. H. F. et. al. (2001). Dicionário biográfico da psicologia no Brasil. Rio de Janeiro: Imago.

Costa, J. F. (1976). História da psiquiatria no Brasil. Rio de Janeiro: Campus.

Figueira, S. A. (1991). Notas sobre a cultura psicanalítica brasileira. In Nos Bastidores da psicanálise (pp. 219227). Rio de Janeiro: Imago.

Galvão, L. A. P. (1976). Pré-história e história da Revista Brasileira de Psicanálise. Revista Brasileira de Psicanálise, 10(1), 7-11.

Le Goff, J., \& Nora, P. (1988a). História: novos problemas ( $3^{\mathrm{a}}$ ed.). (T. Santiago Trad.). Rio de Janeiro: Francisco Alves. (Originalmente publicado em 1974.)

Le Goff, J., \& Nora, P. (1988b). História: novas abordagens ( $3^{\mathrm{a}}$ ed.). (T. Santiago Trad.). Rio de Janeiro: Francisco Alves. (Originalmente publicado em 1974.)

Le Goff, J., \& Nora, P. (1988c). História: novos objetos $\left(3^{\mathrm{a}}\right.$ ed.). (T. Santiago Trad.). Rio de Janeiro: Francisco Alves. (Originalmente publicado em 1974.)

Lobo, R. (1994). As mudanças históricas e a chegada da psicanálise no Brasil. In L. Nosek (Org.). Álbum de família: Imagens, fontes e idéias da psicanálise em São Paulo (pp. 49-55). São Paulo: Casa do Psicólogo.

Mokrejes, E. (1993). A psicanálise no Brasil: as origens do pensamento psicanalítico. Petrópolis: Vozes.

Montagna, P. (1994). Psicanálise e psiquiatria, São Paulo. In L. Nosek (Org.). Álbum de Família: imagens, fontes e idéias da psicanálise em São Paulo (pp. 29-38). São Paulo: Casa do Psicólogo.

Oliveira, C. L. M. V. (2006). História da psicanálise: São Paulo (1920-1969). São Paulo: Escuta.

Perestrello, M. (1992). História da psicanálise no Brasil: o ensino nos institutos. In M. Perestrello (Org.), Encontros: psicanálise \&. (pp. 155-182). Rio de Janeiro: Imago.

Rocha, G. S. (1989). Introdução ao nascimento da psicanálise no Brasil. Rio de Janeiro: Forense Universitária.

Roudinesco, E., \& Plon, M. (1998). Dicionário de Psicanálise (V. Ribeiro, L. Magalhães, Trad.). Rio de Janeiro: Zahar. (Originalmente publicado em 1997.)

Sagawa, R. (2002). Durval Marcondes. Rio de Janeiro: Imago.

Sagawa, R. (1994). A história da Sociedade Brasileira de Psicanálise de São Paulo. In L. Nosek (Org.). Álbum de Família: imagens, fontes e idéias da psicanálise em São Paulo (pp. 15-28). São Paulo: Casa do Psicólogo.

Sevcenko, N. (1992). Orfeu Extático na metrópole: São Paulo, sociedade e cultura nos frementes anos 20. São Paulo: Companhia das Letras. 
Recebido em: 06/02/2013

\section{Notas:}

1 Pesquisa realizada com apoio financeiro da FAPESP.

2 Virgínia Bicudo foi orientada nesta dissertação por Donald Pierson (1900-1995), sociólogo norte-americano que realizou pesquisas sobre relação racial na Bahia entre os anos de 1935 a 1937. Atuou como professor da Escola Livre de Sociologia e Política de São Paulo entre os anos de 1939 a 1959.

3 Noemy Silveira Rudolfer (1902-1988) assumiu em 1932 a cátedra de Psicologia Educacional da Escola Normal Caetano de Campos, posteriormente incorporada à Universidade de São Paulo (Campos et. al., 2001). Foi também professora da Escola Livre de Sociologia e Política de São Paulo entre os anos de 1935 a 1941. A partir de 1949 iniciou análise com Werner Kemper no Rio de Janeiro tornando-se, em 1955, membro fundador da Sociedade Psicanalítica do Rio de Janeiro.

4 Durval Bellegarde Marcondes (1899-1981) formou-se em 1924 pela Faculdade de Medicina de São Paulo. Seguindo os passos do mestre e incentivador Francisco Franco da Rocha, (1864-1933) de quem herdou o gosto e a dedicação pela psicanálise, iniciou o atendimento de pacientes empregando a técnica de Freud nos últimos anos da década de 1920 (Sagawa, 2002).

5 Adelheid Lucy Koch (1896-1980), de origem judia, nasceu em Berlim onde se formou em medicina. Após ter sido analisada por Otto Fenichel, integrou a Sociedade Psicanalítica de Berlim. Instalou-se no Brasil em 1936, onde residiu até a data de seu falecimento. É reconhecida nos anais da historiografia psicanalítica como pioneira da psicanálise na América Latina (Roudinesco \& Plon, 1997/1998).

6 Darcy de Mendonça Uchoa (1907-2003), formado em medicina pela Faculdade Nacional de Medicina do Rio de Janeiro em 1927, atuou como psiquiatra do Hospital do Juquery durante 30 anos, Iniciou em 1937 análise com a Dra. Koch e participou da fundação da Sociedade Brasileira de Psicanálise de São Paulo. Em 1964, tornou-se professor titular do Departamento de Psiquiatria da Escola Paulista de Medicina. (Campos et. al., 2001).

7 Flávio Rodrigues Dias (1899-1994), paulistano, formou-se em medicina pela Faculdade Nacional de Medicina do Rio de Janeiro. Participou ativamente da criação da Sociedade Brasileira de Psicanálise de São Paulo, sendo um de seus pioneiros (Campos et. al., 2001).

8 Posteriormente Lygia Alcântara do Amaral veio integrar-se a este grupo.

9 Prática semelhante foi introduzida no Rio de Janeiro em 1938 por intermédio do Serviço de Ortofrenia e Higiene Mental idealizado por Anízio Teixeira e coordenado por Arthur Ramos.

10 Estas iniciativas foram desenvolvidas sob o patrocínio de José Nabantino Ramos, advogado, jornalista e entusiasta da psicanálise. Em 10 de março de 1945 assumiu o controle acionário da Empresa Folha da Manhã, que posteriormente foi vendida para Otávio Frias em 1962.

11 A profissão de psicólogo foi oficialmente reconhecida no Brasil em 1962 por intermédio da Lei 4.119/62.

12 Entre eles estavam: Caiuby de Azevedo Marques Trench, Humberto Haydt de Souza Mello, Luiz Meyer, Ronaldo Mendes de Oliveira Castro, Stela Maris Garcia Loureiro e Tito Nicias Rodrigues Teixeira da Silva. 